\title{
PICASSO EN HORTA (1898-1899): MISTERIOS DE ARCADIA
}

\author{
POR
}

\author{
ENRIQUE GARCÍA-HERRAIZ
}

\begin{abstract}
The scarcity of extant works from Picasso' first journey to Horta have always puzzled scholars. The truthfulness of the memoirs of Pallarés, Picasso's friend and host in Horta, are now put to question. The author reexamines the various interpretations given to the famous saying of Picasso «Everything I know I learnt in Horta" and analizes Picasso's failure at the National Exposition, Madrid, 1899 and the new path he started from then on. Under the light of two life studies by Picasso recently discovered, the article tracks down the origin of some exciting pictorial ideas later developed.
\end{abstract}

En una entrevista que le hizo Apollinaire a su amigo Picasso entre 1910-11 con la aparente intención de preparar un libro sobre éste que el poeta y crítico de arte nunca llegó a materializar y que cita John Richardson («Picasso: A Life», New York, 1991. Edición en español: «Picasso. Una Biografía 1881-1906", 1995, pág. 489), Picasso se expresa sobre su primera estancia en Horta en 1898-99 de manera un tanto sorprendente y misteriosa: «Por lo que se refiere a mi experiencia emocional más pura, ocurrió a la edad de dieciséis años, cuando viajé a las agrestes tierras españolas (Horta) para pintar» ${ }^{1}$. El mismo Richardson se refiere en el capítulo 7, titulado Horta de Ebro, a que «Como apenas se conserva ninguna obra de Pablo en Horta, no nos sorprende que este periodo suela omitirse, por más que el artista insistiera en su importancia». En «El siglo de Picasso", escribe Pierre Cabanne, que desde Horta, Picasso se enraizó con la tierra ibérica, con el pueblo llano que es la verdad frente a la engañosa enseñanza académica" (pág. 65). Palau dice en la Introducción a la exposición "Picasso: Academic and Anti-Academic» (Yoshii Gallery, Nueva York, mayo 1996, pág. 66) que «cree que Picasso se dio cuenta de que era una persona con facultades excepcionales en Horta». "Hasta entonces su talento natural había sido sofocado o reprimido por la obediencia o el deber»... «En Horta, disfrutó por vez primera al mismo tiempo de libertad y salud".

\footnotetext{
1 Pierre Caizergues en su tesis doctoral de 1977 dio a conocer estas notas encontradas en un par de hojas mecanografiadas conservadas en el Fonds Doucet de París tituladas «Propos de Pablo Picasso». Ver de este autor: «Picasso-Apollinaire. Correspondene», París, 1992, pág. 16.
} 


\section{Los cuadros conocidos de Picasso en Horta}

Hay que reconocer que las menos de setenta obras entre dibujos y óleos que se conservan son muy poca producción para casi ocho meses del prolífico Picasso aunque solo contara entonces entre 16 y 17 años de edad especialmente teniendo en cuenta que solo hay catorce óleos entre paisajes y vistas del pueblo, todos pequeños y ninguno firmado ${ }^{2}$.

A ellos hay que añadir los dos grandes cuadros desaparecidos Idilio y Costumbres de Aragón. Dos ideas diferentes para un mismo propósito: la Exposición General de Bellas Artes de 1899. Aquel, pintado al aire libre durante el verano, pero destruido por una tormenta en la montaña antes de terminarse y el otro, realizado en la seguridad de la casa, con amplio patio, de los Pallarés en Horta en los meses siguientes, perdido su rastro después de figurar en la Exposición de 1899. Palau dice que «Picasso nos ha confirmado - una vez en presencia de Jacint Reventós hijo- que este cuadro había nacido bajo la influencia de Manuel Pallarés. Y a lo que parece fue el celo de éste el que determinó tema y título de la obra» (Picasso Vivo, 1984, pág. 162).

Extraña suerte la de este cuadro de cuya apariencia sólo tenemos como referencia más aproximada el dibujo caricaturesco de Xaudaró con un epigrama satírico al pie, en la sección La Exposición cómica de la revista Blanco y Negro de 13 de mayo de $1899^{3}$. Por la ficha de inscripción localizada por Gutiérrez Burón en el Archivo General de la Administración rellenada a pluma por el propio expositor nos enteramos que las dimensiones eran 1,98 × 2,50 m. y que su autor describía el "asunto", dando simplemente su título, Un patio en una casa de Aragón, en contraste con la ficha de su participación anterior en la que daba una minuciosa explicación de la composición de Ciencia y Caridad. Esto parece sintomático de su menor interés en el segundo intento. La casilla sobre el "precio en que el autor tasa sus obras" la cumplimentó con 2.000 pesetas ${ }^{4}$. El documento lleva la fecha de Madrid, 15 de abril, 1899 y una espléndica firma de Pablo Ruiz Picasso con rúbrica que es de por sí, una joya caligráfica. Al final de la página aparece la firma de Hermenegildo Montes, el amigo de don José que presentaría la obra a la Exposición, seguida de su domicilio en Madrid ${ }^{5}$.

¿Por qué Picasso apenas habló de este cuadro y por qué se sabe tan poco sobre esta pintura «importante»?

Sabartés la menciona en sus «Retratos y recuerdos» (págs. 17-18): En efecto al rememorar su primer encuentro con Pablo en el «tallercito" de la calle de Escudillers Blancs número 1 en 1899, dice: "También hay allí otra tela [antes ha descrito Ciencia y Caridad], pintada en Horta de Ebro, a instancias de su amigo Pallarés. También fue expuesta en Madrid y la premiaron con Tercera Medalla. Luego tuvo Medalla de oro en Málaga.» Esta cita nos enseña al menos que Costumbres de Aragón regresó a Barcelona después de la Exposición Nacional madrileña, la cual se clausuró el 10 de junio y de mostrarse más tarde en Málaga. Sabartés se equivoca o confunde la información verbal, casual, de Picasso sobre las medallas. Sabemos que el cuadro sólo recibió

2 El cuadrito Procesión hacia el Convento de San Salvador (C. Zervos, Catalogue Picasso, París, Cahiers d'Art, 1932 1978, 33 vols.; z. XXXI, 89) único firmado, creemos siguiendo a Palau, que fue hecho ya en Barcelona como una evocación (Picasso vivo n. 276).

3 Carlos Rojas en La Barcelona de Picasso, 1981, pág. 93 alude a que «los epigramas supuestamente ingeniosos deberían bastarle a Picasso para advertir que persiste o le obligan a persistir en un camino errado, el de las medallas para solaz de los Xaudaró, en el supuesto de que no lo supiese».

4 Jesús Rodríguez Burón en su valioso estudio sobre Picasso y las exposiciones nacionales publicado en las actas de C.E. de H.A. 1984, llama la atención sobre una carta del padre desde Madrid (M.P.B. 110-290) donde informa a la familia de lo bien que se pagarán ese año las Terceras medallas (2.000 ptas.) que es la cifra que Picasso asignará como valor al cuadro en la hoja de inscripción. Le recomienda además que "el cuadro sea muy verista».

5 Palau cita a B. Peña Hinojosa, Los Pintores malagueños del siglo XIX, pág. 104. Huelín parece referirse a este cuadro al mencionar "un lienzo de Pablo con tema de costumbres populares» que se trajo a la exposición provincial de Bellas Artes (R. Huelin, Pablo Ruiz Picasso, pág. 188). 
una Mención Honorífica y que la Medalla de Oro malagueña fue destinada a Ciencia y Caridad, pues el cuadro de la exposición de 1899 aunque sí parece cierto que se envió al Liceo de Málaga no obtuvo allí ningún especial reconocimiento ni oficial ni crítico ${ }^{6} . ¿ \mathrm{Y}$ los bocetos que Pablo haría como los había hecho para Ciencia y Caridad? ¿A dónde fueron a parar? Sólo dos hojas de apuntes de las que conserva el Museo Picasso barcelonés -M.P.B. 110.739 y 739 R-parecen estar relacionadas con este cuadro. El dato de Sabartés es importante porque hace recaer en Picasso, autor de la obra, la responsabilidad de su ulterior destino. Observemos que consta que Picasso regaló a su tío Salvador los cuadros Ciencia y Caridad y La Primera Comunión y que éste los mostraba en su casa según refiere su sobrino José Huelín Ruiz-Blasco en su libro Pablo Ruiz Picasso (Biblioteca de la «Revista de Occidente», 1976). ¿A qué se pudo deber una diferencia tan notable de trato para el cuadro de Horta? Al fin y al cabo había sido premiado con otra Mención honorífica, pero más valiosa que la anterior al ser ahora sólo 40 los distinguidos frente a los 122 de la de 1897. ¿Era acaso por la desilusión y disgusto hacia el progenitor que había sido inductor junto al amigo Pallarés de todo el largo proceso incluido el deshonroso epílogo del "fracaso" en la ciudad natal de quien había sido proclamado meses antes nuevo genio del arte español? ${ }^{7}$ ¿La disatisfacción del propio artista que ni siquiera lo cede a un familiar, sino que lo guarda en el estudio pese a ser este tan pequeño? En este detalle creo que está la clave: Picasso advierte que se han burlado de él en la Exposición de Madrid y por eso retiene el cuadro en su estudio para enseñarlo sólo a quien él quiera, pero muy pronto después para servirse del lienzo para pintar sobre él nuevas composiciones como apunta Palau (Ibid., pág. 162). Creemos que nunca se vuelve a mencionar esta pintura sencillamente por que su creador decidió acabar con ella. Este acto de sacrificio de una obra de tan accidentada realización debió ser traumático en más de un sentido. Pero era coherente si partimos de la transformación psicológica operada en Horta. Significaba un rechazo y un cierto menosprecio hacia don José, con quien parece que tuvo alguna bronca airada marchándose de casa, y también para su anfitrión en Horta, Pallarés. Era como un sonoro ¡Basta! a los convencionalismos y las mentiras de las exposiciones oficiales y a las presiones e influjos sentimentales que coartaban su libre albedrío y el fluir de su tesoro más rico, su espontaneidad ${ }^{8}$. Tendrá alguna recaída posterior, pues el padre no se dará por vencido hasta por lo menos 1902 (La Vie...) y la presión ambiental del modernismo catalán y del arte triunfante de Casas le impondrán modelos temporales de estilos ajenos de los que pronto se libra. Ya dijo en la carta a Bas desde Madrid que «había decidido no pertenecer a ninguna escuela determinada».

En Horta se había dado cuenta de sus posibilidades reales como artista pero, tal vez, como dice Palau en Picasso Academic también "se sintió coartado por la presencia de su amigo, pintor como él y no quiso dejarle mal, sino que pareciera ante sus amigos como si igual». Palau alude aquí a la presencia de varios cuadritos con paisajes de tipo académico en los que la creatividad

6 Richardson basándose en la mera existencia del borrador de una carta manuscrita fechada en Malaga el 14 de julio de 1899 que empieza "Querida María Teresa: Recibí tu carta y por ella veo que están ustedes buenos...», (MPB 110.838 R), construye toda una argumentación según la cual Picasso hizo un viaje a Málaga en el verano del 99, "del que no había constancia hasta ahora", en compañía de su amigo Casagemas (lo que el autor deduce simplemente porque su caricatura aparece en una hoja (MPB 110.418) junto a otros apuntes de cabezas y un torero y la mención escrita Teresita Blasco). El motivo principal del viaje sería la presentación del cuadro de la Exposición Nacional junto a otras dos obras Ultimos momentos y un Retrato que Richardson aventura -ya metido en conjeturas- que sería el de Juan Cardona o el de Lola junto a la ventana. Pero, Richardson se equivoca con la identidad del autor del borrador fechado (ya que hay otro de distinta mano en la parte inferior de la hoja que sí puede ser de Pablo) que no es Pablo sino Lola, como se puede comprobar en el mismo catálogo (ver MPB 100.318 R).

7 Por su triunfo en la Nacional, aquel verano de 1897 Picasso fue festejado por los amigos de su padre con champaña en el Liceo malagueño (Palau, Ibid. 131).

8 Ver E. García-Herraiz «La espontaneidad de Picasso y la teoría de la razón vital de Ortega», Goya, núm. $241,1994$. 
de Picasso parece refrenada. «Pero este contenerse le permitía almacenar energía, hacer planes y preparar el futuro... En Horta todo estaba ya dispuesto pero aplazado». De vuelta en Barcelona, Picasso, en la soledad de su estudio, se dispone a tirar por la borda todas las rémoras del academicismo y comienza la liquidación librándose del objeto de su última recompensa oficial.

Además, abre sus puertas -y su corazón mediterráneo- a nuevas y más interesantes amistades que le llevarán al café «Els Quatre Gats». Aparece Sabartés, declina Pallarés.

Los cuadros conocidos de Picasso en Horta que se conservan en su Museo de Barcelona muestran una compenetración íntima con la Naturaleza interpretada con colores suaves, amarillos y ocres (MPB 110.936, MPB 110.120 y MPB 110.107 en especial). Aunque se advierta el progreso de su visión y la mayor seguridad en definir y colorear, reflejan todavía en general su conformismo con el naturalismo de sus maestros académicos y alguno de ellos, como el llamado Vista parcial de Horta (MPB 110.173) (Fig. 1) nos recuerda bastante el estilo del buen paisajista que era Muñoz Degrain. El cuadro de La Mula, que Palau juzga de Horta, con su semiabstracta pero realista sombra, deja en el buen conocedor una sobria impresión velazqueña. En alguno, como en Casas de Horta Palau, 253) (Fig. 2) del que hay un boceto preparatorio en el museo barcelonés, con el gran muro de irregulares ventanas y huecos hay ya una libertad de ejecución y un tratamiento de la luz muy distintos a los de los maestros españoles de la época y quizás por eso Picasso retuvo para sí este cuadrito hasta su muerte.

Dando por supuesto que pintaría y dibujaría más de lo que hay inventariado oficialmente como el Paisaje montañoso (Fig. 3), hay que concluir en que, o se han destruido muchas obras o quedan en paradero ignorado aquellas que hayan podido sobrevivir a los avatares del tiempo, a la guerra y, a la ignorancia y el aislamiento de los primeros poseedores, presumiblemente gentes sencillas de Horta. El descubrimiento reciente de dos cuadros de Horta, con huellas de haber sido maltratados, proyectan resplandores que ayudan, en nuestra opinión, a conocer mejor esta etapa de la formación de Picasso. Los estudiaremos más adelante.

\section{La fascinación de Picasso por Horta}

La primera visita de Picasso a Horta se produce de manera fortuita, sin planificación previa, de modo típicamente andaluz y picassiano. Un amigo íntimo de sus cercanos años escolares de la Lonja, Manolo Pallarés, le invita a su regreso de Madrid de donde viene algo deteriorado de salud a venir con él a su pueblo para pasar las vacaciones estivales que se prolongarían desde junio hasta fines de enero del año siguiente, cuando ya consta por un dibujo fechado en Barcelona, febrero 1899, que Picasso estaba de regreso en la Ciudad Condal. El permiso paterno lo obtuvo a cambio de su promesa de pintar una gran obra para la próxima exposición nacional. La inusitada extensión de las vacaciones es la mejor indicación de lo bien que debió sentirse el joven malagueño en las agrestes y bellas tierras de la comarca de Terra Alta. Juan Perucho, buen conocedor de esta región habla de la fascinación que Horta ejerció sobre Picasso (Picasso, el cubismo i Horta de Sant Joan. Tarragona, 1993). El propio Picasso se refirió en varias ocasiones con su característica espontaneidad a este primer viaje a Horta dando la información básica que recoge esquemáticamente Sabartés (Ibid., pág. 39). Y decía con frecuencia: «Todo lo que sé lo aprendí en el pueblo de Pallarés». Luego, en 1966, Palau encargó a Pallarés que escribiera en unas cuartillas todo lo que pudiera recordar de aquellas vacaciones y así el viejo amigo de aventuras juveniles del genio malagueño compuso un relato que a través de las versiones del propio Palau constituye la referencia más citada desde entonces. La versión más amplia de estas memorias inéditas de Pallarés, es la que se puede leer bajo el título "Picasso y Horta", escrito por Palau mismo y otros colaboradores, que publicado por el Centre Picasso de Horta se puede adquirir 

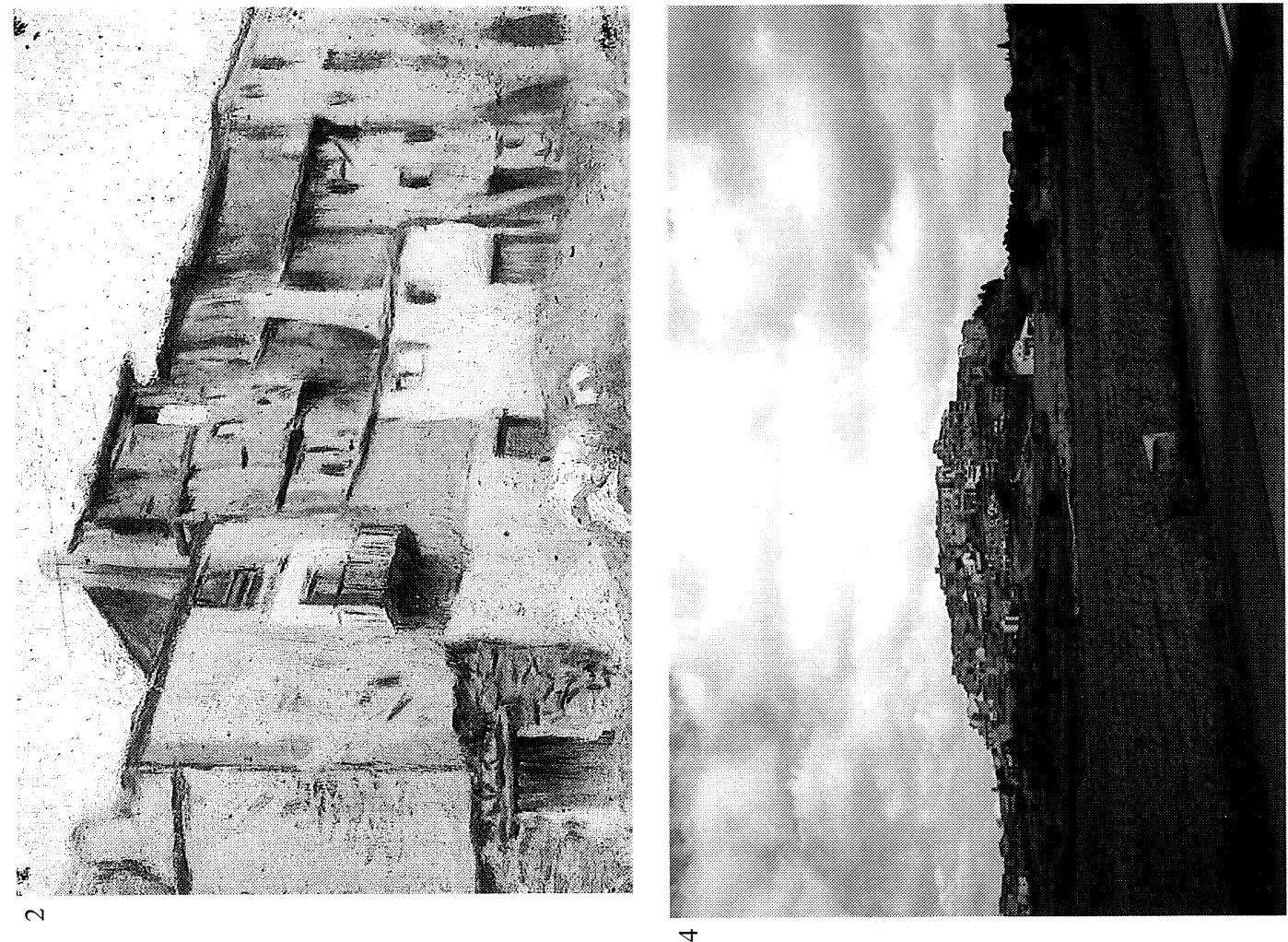

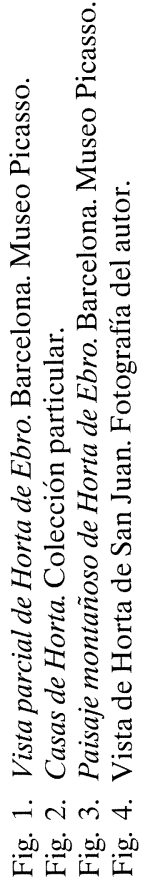
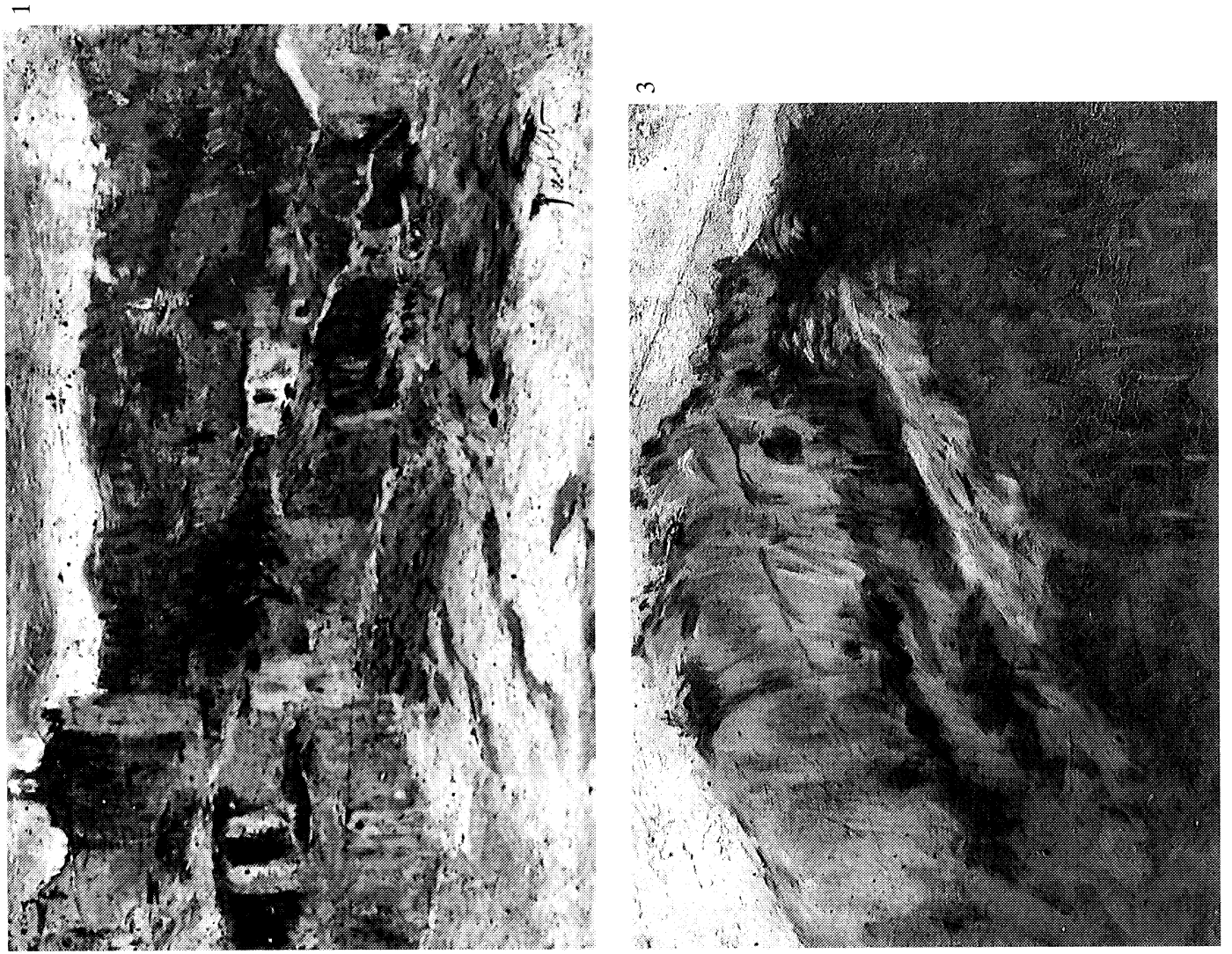
por los visitantes del singular museo instalado en el antiguo Hospital de los Templarios de Sant Joan, un museo donde se pueden ver de manera didáctica las reproducciones de todas las obras realizadas por el maestro durante sus dos estancias en Horta. (Edición en castellano, 1994.)

Si la famosa frase era simplemente como un resumen del recuerdo imborrable que guardaba de su primera estancia en Horta y de lo mucho que había aprendido para manejarse en la vida práctica o si encubría un significado más oculto o más amplio abarcando incluso a su actividad como artista es materia abierta a las interpretaciones más diversas. La interpretación normal del aprendizaje práctico que es la que daban Sabartés y Pallarés ha prevalecido hasta ahora. Pero ya Antonina Vallentin (que tuvo la ventaja de contar con la asistencia directa de su biografiado para la confección de su libro) se siente inclinada a expandir el sentido de la frase, pues escribe después de enumerar labores como ordeñar las vacas, hacer un nudo sólido, etc.: "Pero este saber de cosas humildes no fue lo único que aprendió en estas vacaciones. Allí adquirió para el resto de su vida el hábito de una preciosa intimidad» (Picasso, París, 1957, pág. 123). Pierre Cabanne (Ibid., pág. 64) deja abierta la interpretación expansiva que incluye su toma de conciencia del valor del trabajo manual y del significado de la libertad. Y, últimamente, Palau en "Picasso Academic» ha reconsiderado la interpretación tradicional que él también aceptaba en Picasso Vivo, en favor de otra que tenga en cuenta el cambio psicológico de reafirmación o más bien de descubrimiento de su excepcionalidad como artista (y como persona) que se produce en Pablo durante su vida en Horta.

En efecto: Palau, citando a Fermigier (Picasso Les Livres de Poche, 1969) para quien Picasso quiere decirnos de esta forma que no debía nada a nadie como pintor, pues todo lo que sabía lo traía ya aprendido de Horta (donde no tuvo maestros), pone en relación esta interpretación con la respuesta que da Picasso a Apollinaire tomando literalmente su declaración de que fue a Horta "a retirarse para pintar», y no a pasar unas simples vacaciones. «En Horta -dice PalauPicasso se convenció de lo que siempre había sospechado y que estaba latente en él: que con su talento y su fuerza podía conquistar el mundo" (Ibid., pág. 68).

Alguien que lo conoció entonces recién llegado del campo, describió así su impresión: «Al pasar delante de él, para despedirme, inicié una reverencia, turbado por la fuerza mágica que se desprendía de toda su persona.» Era Sabartés ${ }^{9}$.

\section{Los dos cuadros de Horta reaparecidos}

En la Fontana d'Or, centro cultural de la Caixa de Girona de esta ciudad, en la exposición "Picasso i Catalunya" que conmemoraba el centenario de la llegada de Picasso a Cataluña (Noviembre de 1995) se mostró públicamente por primera vez un cuadro que según el comisario de la exposición Josep Palau i Fabre corrresponde a esa primera etapa del artista malagueño en Horta.

Se trata de un óleo sobre lienzo de $49 \times 31 \mathrm{~cm}$. en buen estado de conservación pero con algunos arañazos y señales de haber estado mucho tiempo doblado. Representa a un muchacho desnudo de aspecto gitano sentado sobre una especie de manta de color verde que se enfrenta al espectador entre desconfiado y desdeñoso (Fig. 5).

Las referencias escritas esenciales sobre este cuadro y su compañero aparecido al mismo

\footnotetext{
9 J. Sabartés «Picasso: Retratos y recuerdos», 1953. Hay que tener en cuenta que en su segundo libro «Picasso Documents iconographiques» (París, 1954), pág. 42, Sabartés amplía la interpretación del dicho a categorías mentales: «allí es donde aprendió a calibrar el valor de una palabra dicha oportunamente, a hacer comparaciones, a apreciar las diferencias...".
} 
tiempo son las siguientes: a) En la revista de arte Goya núm. 221 de abril de 1991, quien esto escribe, publica un artículo donde los da a conocer en unión de otro dibujo, los tres reaparecidos el año anterior en una subasta madrileña: «Picasso pre-azul: Tres inéditos de Picasso del trienio 1897-1899». b) La revista The Journal of Art de Nueva York los publica bajo el título "Unknown works by Picasso discovered in Spain» March 1991 p. 3. c) Por encargo de la casa Sotheby's, en Abril de 1995, Josep Palau i Fabre, autor de varios libros sobre Picasso, reconocido internacionalmente como principal experto picassiano en el periodo de juventud del artista, concluye su estudio y certifica que las tres obras son auténticas de Picasso y que los óleos corresponden a Horta 1897-8 titulándolos respectivamente Gitanillo desnudo, sentado y Hombre desnudo de espaldas ${ }^{10}$ (Fig. 6).

Desde un punto de vista estilístico, estas pinturas chocan contra los conceptos mas comunes sobre el proceso evolutivo de Picasso en tanto muestran ya rasgos e ideas pictóricas propios que son anticipos claros de lo que pintará en París en las décadas siguientes. Constituyen los escalones previos al gran cuadro de Lola junto a la Ventana y el Retrato de Juan Cardona, ambos hechos en Barcelona en 1899 que son ya obras que se insertan en la estética del nuevo siglo pues se distancia tanto del modernismo como del academicismo. No es fácil admitir para los autores que han ignorado o menospreciado el periodo español de la infancia y adolescencia del artista, que Picasso cuando salió de Barcelona con destino a París ya llevaba un bagaje de ideas originales.

Quiero recordar que en el artículo mencionado, reconocí sendos cuadros como obras indiscutibles de Picasso basándome en las fuertes semejanzas y paralelismos con otros cuadros y dibujos conocidos del maestro malagueño anteriores o coetáneos. Supuse que el modelo del primero sería un gitanillo de la calle y el lugar donde fuera realizado, el estudio de Picasso en Barcelona o una clase del Círculo Artístico el regreso de las vacaciones de Horta que terminarían en Febrero de 1899. Pero cuatro años más tarde, Palau, al estudiar detenidamente en Barcelona sendos óleos, asegura persuasivamente que el modelo era el mismo muchacho que aparece en un dibujo hecho en "los Ports de Horta" que conserva el Museo Picasso de Barcelona (MPB 110.786 R. y Palau, Picasso vivo, pág. 149 y cat. n. 262) (Fig. 7). En el citado artículo de Goya yo había mencionado y reproducido este dibujo por su semejanza estilística con el cuadro reaparecido. Al poderse contemplar en la exposición de Gerona uno junto al otro, el dibujo del Museo y el cuadro, es fácil dar la razón a Palau y reafirmarse en que se trata de dos representaciones de la misma persona, siendo probablemente el dibujo un boceto o la idea matriz de la pintura. Palau también asigna a Horta el cuadro del Hombre desnudo. Al situar sendos cuadros en Horta se explican mejor algunos de sus peculiares rasgos. El cuadro del gitanillo no encaja bien como una simple obra académica con modelo de clase tanto por la pose del personaje y el lugar, que se ve que es un cuarto interior con una percha y una chimenea de estufa. Ni aquí ni en el caso de la pintura del Hombre desnudo de espaldas se reconocen las huellas típicas de una clase de Academia de arte ni de la presencia de un profesor supervisando el ejercicio del alumno copiando un modelo. El cuadro del Gitanillo es más bien un retrato, pero un retrato donde Pablo, libre de la tutela profesoral, pone en práctica sus nuevas ideas y experimenta con procedimientos pictóricos en parte inspirados por sus recientes visitas al Museo del Prado, particularmente Velázquez. Aunque los cuadros de academias que Picasso hizo en la Escuela Oficial de Bellas Artes de Barcelona (véase por ejemplo el Hombre sentado en un taburete MPB 110.050 de 1896) casi siempre reflejan ya el temperamento original de su autor que deja a propósito zonas sin acabar o sucintamente expresadas con uno o dos líneas marcadas por trazos gruesos de pin-

10 El estudio de Josep Palau i Fabre sobre estas dos obras está incorporado -en inglés- al texto del catálogo de la Exposición de la Galería Yoshii de Nueva York (Picasso Academic and Anti-Academic, Yoshii Gallery, New York, 1996). 


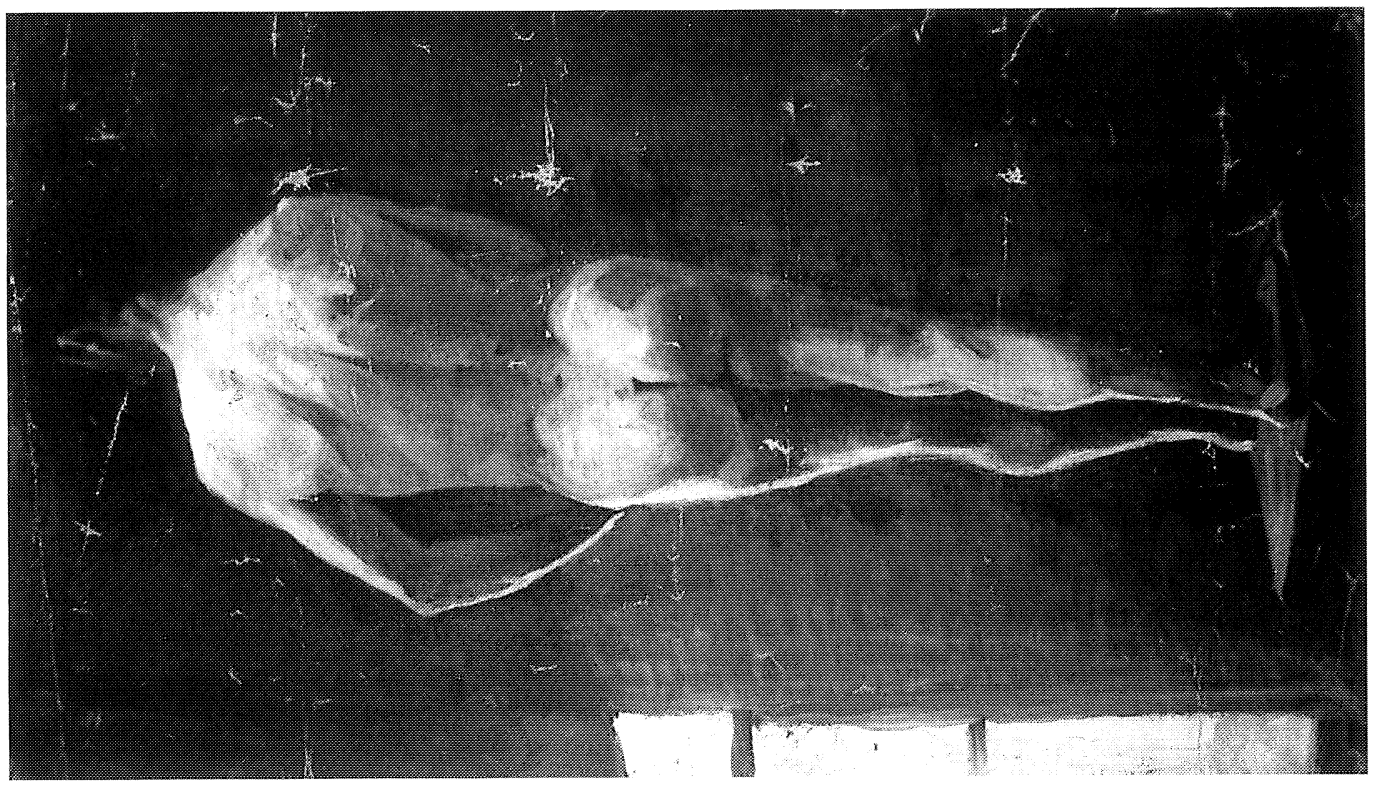

6

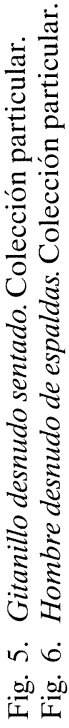

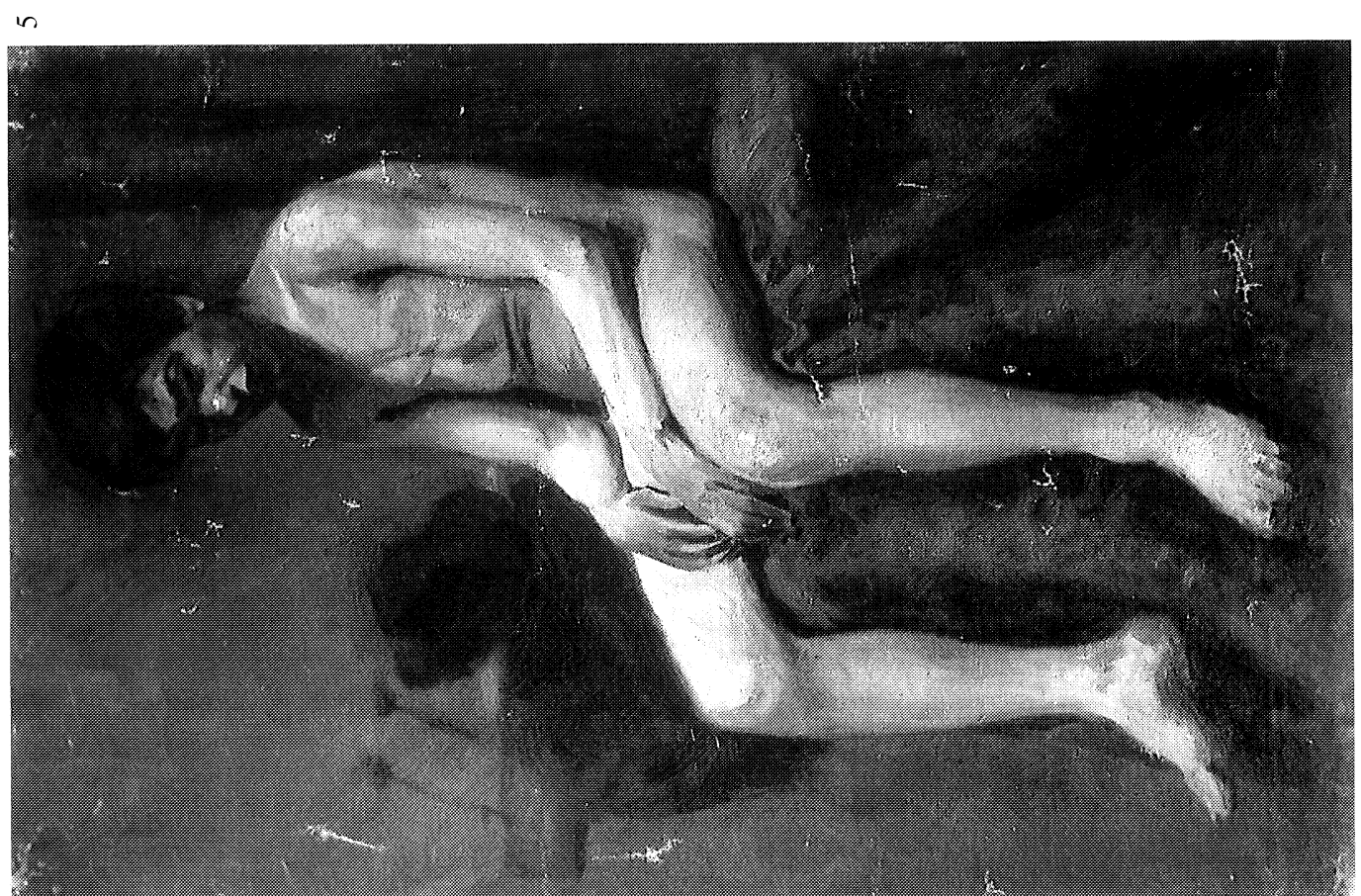


cel, casi nunca escapan del inevitable aire didáctico-escolar que constituye la maldición de este género: Figuras de cansados hombres maduros obligados a permanecer horas bajo la luz de una bombilla inocuamente desnudos o sosteniendo un absurdo bastón como si fuera un instrumento de trabajo.

Estos cuadros son bien diferentes a las academias clásicas. Picasso en la paz de Horta, terminado el verano y la aventura de los Ports, se encierra en un cuarto de Can Tafetáns -la casa de los Pallarés- y reemprende la tarea de pintar el gran cuadro para la Nacional. Allí improvisa su propia escuela utilizando a gentes de su entorno como modelos ${ }^{11}$. Pero en esta clase de arte no habrá profesores. El mismo será profesor y alumno. De aquí el carácter de pinturas laboratorio que asignamos a estos estudios del natural de Horta. Palau anota en «Picasso Academic....: «La pincelada se ha librado ya de toda sumisión explicativa y revela su deseo de ser totalmente autónoma». Algunas de las ideas que germinaron en este laboratorio se incorporan a su repertorio propio y de ellas se servirá más adelante. En mi artículo de Goya n. 221, me permitía indicar varias de estas ideas pictóricas reconocibles en el cuadro del Gitanillo: En primer lugar que puede ser la inicial plasmación de Arlequín tal cual aparece en Arlequín sentado (Z. XXII, 237) (Fig. 8) que luego utiliza en los arlequines-retratos de Salvadó (Z. V. 17-23). También parece ser el principio de otra evolución antropomórfica que pasa por los geométricos jóvenes de tez oscura y cabeza inclinada de $1908-9$ (Z. II* 77, 117, 172) que conducen al cubismo. Y en la nota 7 apunté que el origen de la esquematizada mano de la "demoiselle» central que agarra el paño blanco en el gran cuadro de Les Demoiselles d'Avignon podía estar en la mano derecha de este muchacho moreno que está pintada de una manera que ya no es ni academica ni naturalista. Palau se fija también en la originalidad del tratamiento pictórico de las manos del gitanillo: «Estas manos (Fig. 9), para la descripción de las cuales el pincel se ha deslizado con placer, como si fueran una prolongación fluvial de los brazos son un precedente obvio de las Manos de 1921 (Inv. M 227). Esta interpretación casi fluvial de las manos, Picasso la llevará a sus últimas consecuencias en un retrato de Marie-Thérese de 1932 (Z. VII, 364) donde la mano se desparrama hasta llegar a tener seis dedos». (Picasso Academic... p. 140). Sobre el otro cuadro volveremos más adelante.

Pero el descubrimiento del cuadro del gitanillo cobra una dimensión inesperada al relacionarlo con el testimonio de Francoise Gilot -compañera sentimental durante diez años y madre de dos hijos comunes con Picasso- que cita la autora Arianna Stassinopoulos Huffington en su libro traducido al español bajo el título "Picasso Creador y Destructor» (Barcelona Círculo de Lectores 1989. La edición original en inglés «Picasso Creator and Destructor» Simon and Schuter apareció un año antes).

Según este libro (págs. 41-43 en el texto inglés y 39-41 en el español) «Pablo y Manuel, en compañía de un gitanillo, fueron a explorar las montañas... etc.». La manera en que Pallarés contaba sus recuerdos de aquellas largas vacaciones de Horta era como si solo Picasso y él exploraban Horta juntos; pero "según lo contó Picasso en la única ocasión en la que habló sobre esta apasionada amistad, eran siempre él y el gitano» ${ }^{12}$. «Pallarés era (tan aburrido) como un pedazo de pan duro" (¿un mendrugo?). El libro continúa explicando que «el gitano y Pablo mantuvieron

11 «Por la tarde, así que acababa de pintar, Picasso iba a buscar a su amigo Pallarés al lagar de aceite que su familia tenía cerca de la carretera donde éste cultivaba su afición.» (Picasso vivo, pág. 151). Es decir que Picasso en Horta, por razones que no explica Pallarés, pintaba solo, separado de su anfitrión. ¿Imposición de Pablo? o ¿pura convenencia? Pallarés es evidente que pintó lo que tenía más a mano, pues consta que presentó a la misma exposición un cuadro titulado Un molino aceitero.

12 La versión española ofrece una traducción libre del párrafo. El original en inglés citado expresa que Picasso relató a Françoise Gilot el episodio del gitanillo de Horta «una sola vez en su vida» mientras que el texto en español dice: «Picasso cada vez que se refería a su apasionada amistad, citaba solamente al gitanon. 
una amistad íntima y en la cueva o en la aldea, estaban siempre juntos. Dice que el gitanillo era dos años más joven que Pablo y que también pintaba. «El gitano le enseñó el significado del canto de los pájaros y el remoto movimiento de las estrellas y como establecer una alianza con la naturaleza, los animales, las plantas y lo invisible. Juntos esperaban el diario milagro del atardecer y daban largos paseos por los ásperos caminos de la montaña» 13 «Pallarés, desplazado y excluído, se vengó más tarde omitiendo toda mención del gitano en su relato de la vida de Pablo en Horta». Stassinopoulos llega a decir que la relación con el gitano fue «el punto crucial de su vida» y cita a Ramón Gómez de la Serna quien dijo en 1923 "que en la gran nación de los gitanos del arte Picasso es el mayor gitano de todos» y que «Pablo siempre profesó un especial y secreto cariño a esta definición".

Pero el libro cualifica después la amistad de Picasso con el gitanillo en términos que han escandalizado a otros autores y que suscitan dudas sobre las intenciones de Francoise Gilot que quizás pretendía dañar la imagen de su odiado ex-amante. «Mantuvieron íntimas relaciones que tuvo que cortar el gitano al darse cuenta que en el paraiso que era la vida en Horta para los dos jóvenes se interponía el mundo fuera de Horta. Y el gitano desapareció un buen día dejando a Pablo desconcertado" ${ }^{14}$. La fuente de esta información es, según la autora, Francoise Gilot en las varias entrevistas que tuvo con ella para la preparación del libro.

John Richardson -el otro gran biógrafo picassiano- en el mencionado libro de 1991 pág. 49, alude a la historia del gitanillo, la niega y cree que Stassinopoulos se confunde de muchacho pues en el relato de Pallarés solo se menciona a un chico de unos diez años que llevaba la mula con las vituallas que el autor inglés-neoyorquino identifica con el Cabrero del dibujo del Museo Picasso de París («Jeune garçon appuyé dans une baton et etudes» MPP 411. Z. VI, 62) (Fig. 10).

En realidad este muchacho, según el texto de Palau (Picasso vivo, pág. 148) y el propio de Richardson que siguen a Pallarés, pernocta en la montaña con Pallarés y Picasso un total de tres días, dos de ellos, ya con el hermano menor de Pallarés, Salvadoret, de vuelta del pueblo, en la cueva de los Puertos donde habían instaldo sus caballetes para pintar al aire libre. La segunda noche estaba borracho. Ya había tenido tiempo pues, para hacerse amigo de Pablo. Después, al cuarto día -siempre según Pallarés- regresan Salvadoret y el muchacho con el perro y ya se quedan solos Pallarés y Picasso. No se vuelve a mencionar a este muchacho que es descrito como el chico de la mula por Pallarés, un chico apoyado en una vara según el Museo Picasso de París y un pastorcillo según el Museo de Barcelona. Es decir, que el muchacho aparece como un personaje secundario en esta historia de aventuras juveniles contada por el viejo Pallarés pero como el principal protagonista según la historia transmitida por Françoise Gilot. Richardson en su afán de ofrecer una interpretación propia a cualquier punto oscuro en la vida de su biografiado traslada la escena desde las montañas de Horta y el verano de 1898 al barrio parisino de Montmartre y al invierno de 1904, pues cree más plausible asignar la supuesta amistad de Picasso con un gitano a su relación con el guitarrista flamenco Fabián

13 Según Gilot-Stassinopoulos el gitanillo era también pintor y «los tres pasaban gran parte del día pintando», pág. 41 , ibid.

14 Este relato sobre el gitanillo tiene mucho que vier con prácticas conocidas de la llamada magia gitana: La época más favorable a la magia amorosa es la fiesta de San Juan (noche del 23 al 24 de junio) que sigue al solsticio de verano, cuando en la mañan se coge el ramillete de artemisa que protege contra el mal de ojo. Ciertos ritos gitanos requieren determinadas horas: la medianoche, la hora en que sale el lucero de la tarde y el momento en que desaparecerá la última estrella del alba son perfectamente adecuados. (Extractado de Bernard Leblon "Los Gitanos de España", págs. 150-1, Ed. Gedisa, Barcelona, 1993 trad. del francés «Les Gitans d'Espagne», Presses Universitaires de France, 1985.) Los únicos referentes temporales evidentes en un mundo sin cronómetros, dice Leblon, son los movimientos de los astros, las campanadas d la iglesia y las fiestas religiosas. Leblon, en carta al que suscribe, duda de la existencia del juramento gitano por sangre. 
de Castro, personaje de la bohemia parisina con quien Picasso tuvo que compartir habitación durante un breve periodo en el Bateau Lavoir al posesionarse del antiguo estudio de Paco Durrio. (Ibid., nota 6, Cap. 7). Aunque el propio Richardson no habla de una relación homosexual nos parece una interpretación muy forzada e improbable. Françoise Gilot no puede haberse equivocado de personas, lugares y fechas tan de plano.

El meollo de la cuestión está en saber si Pallarés ocultaba o no que les acompañaba otra persona en aquellas semanas de vida salvaje durmiendo en una cueva de la montañas. Richardson confía en la veracidad de Pallarés a quien considera "un testigo más fidedigno» ${ }^{15}$. Palau, el mismo que encargó a Pallarés el relato escrito de sus memorias de Horta, supone ahora, que Pallares, muy celoso de la exclusividad de su amistad con el genio, «no le reveló toda la verdad» ${ }^{16}$. En la introducción antes citada de la exposición de Yoshii en Nueva York (pág. 66, Paradise Regained) Palau reitera su actual caracterización de un Pallarés celoso y posesivo que seguramente ocultó la existencia del tercer amigo de Horta. «Esta tercera persona fue postergada por Pallarés en sus conversaciones y en sus memorias... ¿Sería este tercer amigo el niño gitano que pintó Picasso?».

Norman Mailer en su reciente libro sobre la juventud de Picasso («Portrait of Picasso as a young man», New York, 1995, pág. 23) hace amplio uso de esta información sobre el gitano de Horta y aunque critica por razones literarias el texto de la Stassinopoulos, parece darle crédito para reforzar la imagen que refleja su libro de un Picasso contradictorio y ambiguo en sus preferencias sexuales.

La existencia de un tercer protagonista - no un simple acompañante- durante la larga estadía en los Puertos aparece implícita en el relato de una conversación de Picasso con Genevieve Laporte que ésta reproduce con imprecisiones en su libro «Si tard le soir» (París, 1974) citado por Palau en la nota sobre el cuadro del gitano del catálogo de Girona -y de nuevo en «Picasso Academic, pág. 67»- que aquí reproducimos en su versión española según se lee en la página 42 del libro "El amor secreto de. Picasso»: «También he hecho camping antes de que se pusiera de moda, con dos amigos por las montañas de España. No vimos a nadie durante un mes. Ibamos desnudos. Hasta pintamos algunas peñas ¡Los cazadores furtivos eran los únicos que podían vernos. Nos enteramos al volver.... ${ }^{17}$. Estas frases parecen indicar que o bien existía desde el principio otro muchacho que permanece en la montaña con la pareja de amigos o que el muchacho de la mula se ha quedado arriba y regresa solo al pueblo Salvadoret. Aluden sin lugar a dudas al periodo en que se quedan solos en la cima junto a la cueva que les servía de refugio nocturno durante tres o cuatro semanas, según el cálculo de Palau. O estaban solos Pallares y Picasso o les acompañaba el misterioso gitanillo. Las referencias a la edad no creemos que deban ser tomadas al pie de la letra. En primer lugar resulta difícil aceptar que el muchacho tuviera diez años y le confiaran un mulo y su carga. En el dibujo de Barcelona el rostro aparece aniñado o incluso feminizado mientras que en el de París, pues evidentemente se trata del mismo modelo, sus facciones tienen mayor dureza y su cuerpo más vigor. Bien puede ser un chico de catorce

15 Con respecto a la fiabilidad de los testimonios frecuentemente encontrtados de Pallarés y Sabartés, es obvio que Richardson simpatiza más con el primero y califica a Sabartés de envidioso y tremendamente celoso (ver mi crítica del libro de Richarson en Goya, núm. 255, 1996).

16 Carta a E.G.H. de 26-6-95.

17 Richardson recoge este mismo pasaje del libro de Laporte que cita en las notas, pero no parece advertir que el texto habla de Picasso y "dos amigos» que acampan en las montañas, lo cual contradice la versión de Pallarés que él acepta. Ibid., pág. 492. Atención: la traducción al inglés del libro de memorias de Genevieve Laporte llamado Sunshine at midnight (Macmillan, New York, 1975), no incluye este párrafo. Richardson incluye en su bibiliografía la versión original: Un amour secret de Picasso, Mónaco, 1989. Esta frase final que Genevieve ha transcrito a medias claramente alude al final de la guerra con Estados Unidos sobre Cuba y Filipinas (13 de agosto de 1898): "Nos enteramos al volver ... que había terminado la guerra». 
años. Y el gitanillo "dos años menor que Picasso" que cita el libro de Stassinopoulos, contaría entonces catorce años ya que en el verano del 98, Pablo, como el mismo recuerda a Apollinaire, tenía dieciséis años. Y aun Picasso pudo creerlo mayor de lo que en realidad era.

Quiero añadir otro testimonio gráfico de aquel verano en Horta. En el catálogo del Museo Picasso de Barcelona hay una hoja de Horta con apuntes y anotaciones que puede tener relación con el misterioso gitanillo (MPB 110.747 R, pág. 396). El catálogo lo titula Varios tipos aragoneses, Horta, 1898. En efecto, Picasso ha abocetado varias figuras y cabezas de ambos sexos con la típica indumentaria aragonesa y ha anotado con el mismo lápiz las siguientes palabras: « $\mathrm{G}$ Greco, Velázquez INSPIRARME!» y en el extremo inferior de la hoja, "QUERIDO, QUERIDO AMIGO» (Fig. 11). Da la impresión que Pablo al disponerse a acometer la ejecución del gran cuadro para la Exposición Nacional que iba a llamarse Idilio y que se destruyó por una tormenta en la montaña, invoca a sus maestros favoritos del Museo del Prado y también tiene un pensamiento para un querido, querido amigo, innominado. Alguien muy querido, pero a quien no se atreve a nombrar. Sería deseable que doña Françoise Gilot desde su domicilio neoyorquino confirmase y ampliase su precioso testimonio ${ }^{18}$.

Conclusión: creemos que el tercer amigo de los Ports es el chico cuya imagen vemos en sendos dibujos y que Pablo, de regreso en Horta, algún tiempo después, trasladó en un empeño más serio al lienzo. En efecto: el cuadro Gitanillo desnudo, sentado, refleja el ambiente de un interior en un mes frío. Hay una manta y el chico, que tiene el cabello más crecido, está acomodado con la espalda muy cerca de un tubo de estufa o chimenea ${ }^{19}$. Parece lógico, pues, asumir la existencia de un segundo amigo íntimo de Picasso en Horta y se puede colegir, que buena parte del fuerte atractivo que Horta despertaba siempre en el recuerdo de Picasso tuviera algo que ver con este misterioso personaje, que bien pudiera guardar la clave de la "emoción más pura» de su vida, según la declaración que hizo a Apollinaire en 1910.

\section{El gitanillo y los arlequines picassianos}

En mi artículo citado de GOYA al advertir, con no poca sorpresa, las semejanzas de pose y carácter de este grave retrato velazqueño del muchacho gitano con algunos imágenes picassianos de arlequines, comenzando con el Arlequín sentado sobre fondo rojo, de 1905, me atreví a sugerir que en el cuadro reaparecido se hallaba el germen o la primera plasmación de la creación iconográfica, probablemente, más célebre de Picasso. Encontré un párrafo premonitorio de Eugenio d'Ors -que tanto presumía de conocer mejor que nadie a Picasso-, que resumí en las notas que no se publicaron en dicho artículo y que transcribo a continuación: «D’Ors se expresa retóricamente como si hubiera visto este cuadro al decirnos "que las siluetas de Arlequín no han aparecido en la obra del artista durante un determinado periodo, sino en todas las épocas, desde los espectáculos de la infancia...”” (Picasso, Aguilar, 1945, pág. 87).

Palau al estudiar Horta en "Picasso Academic...» vuelve al misterio del gitano. Lo relaciona con los diez bocetos de fines de 1908 y principios del 1909 (que ya estudió en detalle antes en Picasso Cubismo, págs. 117-119), representando una escena que él llama Carnaval en la taberna (Fig. 12) y en la cual varios personajes (una mujer de pueblo, Arlequín, una figura de San Anto-

18 El libro de memorias redactado por Françoise Gilot con la colaboración de C. Lake, "Life with Picasso", publicado en vida del artista, en 1966, no alude a esta historia en su rico y útil texto. Es, sin embargo, generalmente considerado como uno de los fundamentos de la leyenda antipicasso.

19 Palau en Picasso Academic, pág. 69 se inclina datarlos en agosto o septiembre principalmente por razón de la desnudez de los modelos, pero después verbalmente me explicó que no había reconocido que el objeto oscuro alargado detrás del muchacho es una estufa. 

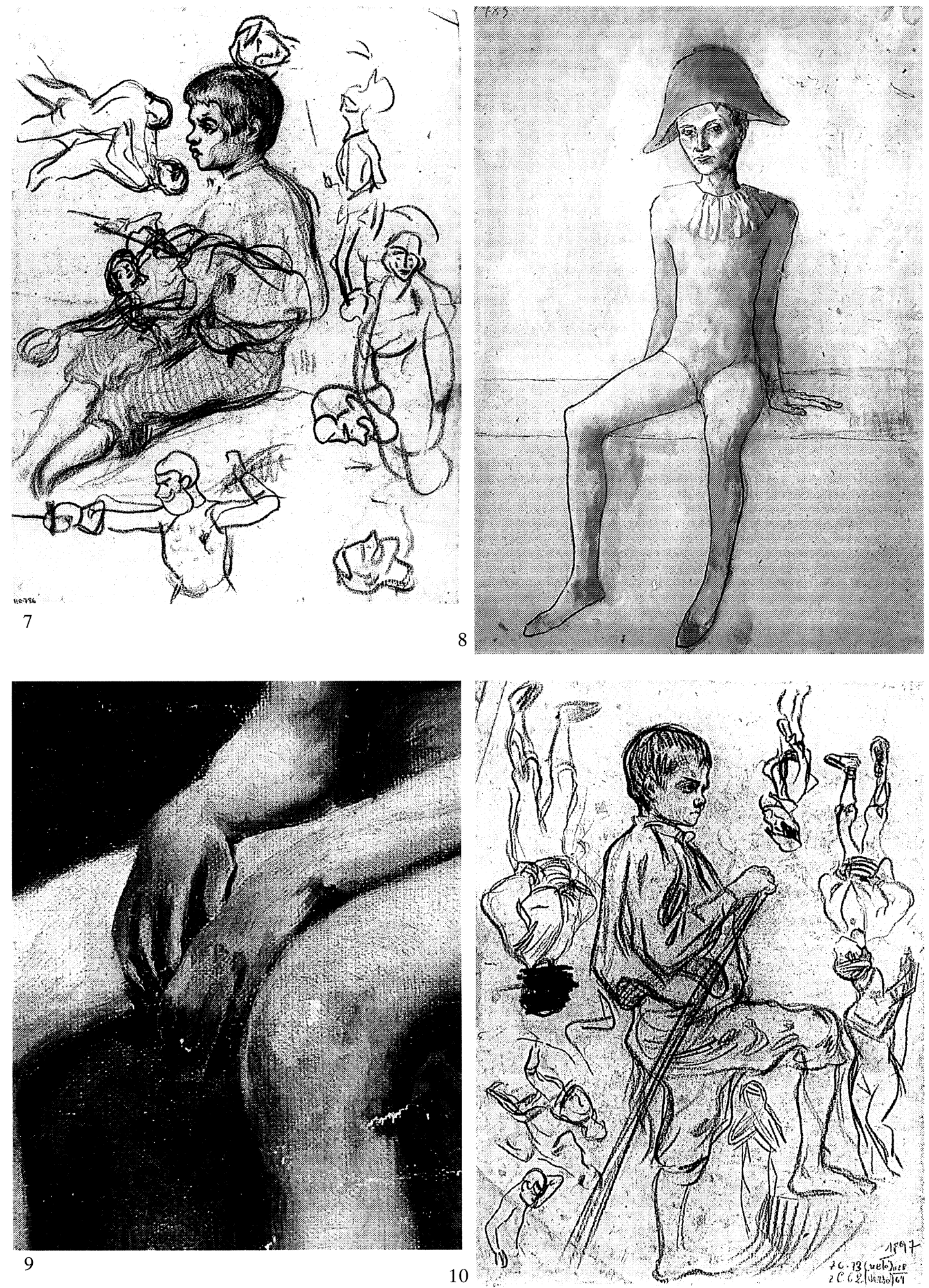

Fig. 7. Pastorcillo de Horta y otros apuntes. Museo Picasso.

Fig. 8. Arlequín sentado. Colección particular.

Fig. 9. Gitanillo desnudo, detalle. Colección particular.

Fig. 10. Cabrero. París. Museo Picasso. 
nio) situados detrás de una peculiar mesa rústica catalana sufren diversas transformaciones hasta terminar por eliminarlos y convertirlos en Panes, frutero y fruta, reposando sobre la misma mesa, verdadero bodegón cezanniano "desprovisto de toda literatura y de todo los que no sean problemas pictóricos ${ }^{20}$. Pues bien, Palau piensa que Picasso evocaba en aquellos bocetos una movida noche de víspera de San Antón, pasada en una taberna de Horta un 17 de enero de 1899, y se pregunta que si supiéramos a quienes representaban la mujer que sirve la fruta de un plato y «el travieso Arlequín que se mezcla entre los comensales y transforma la escena por arte de magia", podríamos encontrar respuesta a las cuestiones que plantea «su estancia en los Ports en compañía de un gitanillo y una posible aventura femenina antes de iniciar el regreso a Barcelona». ( $\mathrm{Pi}$ casso Academic, pág. 69.)

Ahora, a los elementos formales del cuadro que llamaron mi atención, al escribir el artículo de la revista GOYA se unen los de tipo conceptual: El amigo gitano de Horta, solitario y libre como el aire de las montañas, maestro en saberes arcaicos de la tierra y del firmamento, sexualmente extrovertido, quizás andrógino, entre mágico e irreal ${ }^{21}$ pudo muy bien ser el modelo humano en el que Picasso se inspiró para plasmar la figura de Arlequín. El nombre y el envoltorio del personaje los sacó de París; pero una vez más como cuando Picasso trataba de explicar a Kahnweiler la gestación de Les Demoiselles d'Avignon, el tema, el espíritu, venían de mucho antes y de muy lejos. En el artículo de GOYA seguí el rastro del gitanillo-arlequín a través de sucesivas reencarnaciones: Vuelve el personaje en el año 1923, transfigurado en la pareja de retratos del pintor Jacinto Salvadó que presentan obvias semejanzas con aquel cuadro. Arlequín vuelve también en el fulgurante y bello cuadro, hoy en el Museo Thyssen de Madrid, que lo representa coqueto y narcisista con un espejo ante su rostro. En este mismo año, Picasso realiza varias pinturas, plenamente figurativas, utilizando de modelo a su mujer, la rusa Olga y según la tesis de William Rubin y Pierre Daix, también a la señora norteamericana Sara Murphy nueva amiga y divertida anfitriona del círculo social de la playa de Cap d'Antibes. Y trabaja como obsesionado, en bocetos en los que añade o suprime personajes, en un cuadro importante, el que una vez terminado se denominará La Flute de Pan (Fig. 13), un cuadro de misterioso significado que se guardará para sí mismo hasta su muerte. Pero como dice Pierre Daix: «con Picasso las cosas nunca son sencillas. Incluso si Arlequín es encarnado por otra persona, para Picasso continúa siendo el doble portador de sus sueños y de sus temores» ${ }^{22}$. Resumiendo: Para Rubin y Daix, $L a$ Flauta de Pan, con la eliminación final del personaje femenino de los bocetos, en el declinar de la suerte de Olga, representa el amor frustrado entre Sara y Picasso. Para mí esta escueta figuración de los dos serios adolescentes, uno de ellos claramente identificado con Picasso, ante un horizonte mediterráneo cargado de transcendencia, tiene más que ver con la nostalgia y los re-

20 Z. II*134. Palau II, 329.

21 La presencia de los gitanos en Cataluña es señalada en los "Anales de Cataluña» de Narcís Feliú de la Peña desde 1447. Varios autores aluden al gusto de los gitanos - quizás por pura necesidad al ser rechazados en los pueblos- de habitar en las cuevas de las montañas. Ejemplos bien conocidos son los gitanos de los Cárpatos, los Balkanes y los del Sacromonte de Granada que llegó a ser el pueblo troglodita mayor del mundo. En cuanto a costumbres, algunos libros antiguos españoles sobre gitanos muestran prejuicios raciales muy arraigados, y uno quer consulté en la Biblioteca Nacional cuyo título lamento haber extraviado, señala que "los gitanillos parecen carecer de sexo... solo cuando transcurre algún tiempo principian a distinguirse los seres masculinos y los femeninos...". "A los dieciséis años muchos se ocultaban para evitar el alistamiento militar». Las fuentes sobre los gitanos españoles son muy copiosas. Leblon, antes mencionado, da en su excelente libro una bibliografía general de más de doscientos cincuenta títulos. Sobre la imagen del "gitanismo" que se prolonga hasta el siglo xIx, Leblon dice que "pasa a ser el contraste moral del "mundo civilizado", la antisociedad». Y cito textualmente: “¿No los presentó Cervantes, con un matiz burlesco no siempre bien advertido, como los sobrevivientes de la Edad de Oro y los portavoces del Beatus Ille horaciano?». "Representan en Cervantes... un ideal del amor libre», Ibid., pág. 39.

22 Ver Arlequín con espejo y La Flauta de Pan, Picasso, 1923. Museo Thyssen-Bornemisza, Madrid, 1995, con textos de Tomás Llorens, Pierre Daix y A. Muñoz Molina. 
cuerdos de Horta, y puede ser una evocación (que tiene algo de invocación de ayuda), del lejano amigo de los sueños compartidos en la libertad de la Naturaleza ahora que se despide de la juventud en un ambiente -el de Antibes- en el que se siente extraño.

En cuanto a la tesis de la relación homosexual entre el gitanillo y Pablo, aun dejando un amplio margen de duda por la complejidad del tema, considerando la más que probada afición de Picasso por el sexo contrario en el curso de su larga existencia, hay que pensar que se tratara o de una errónea o malévola interpretación de la Gilot, de la confidencia de aquel o que si existió un episodio erótico habría que explicarlo como una anécdota pasajera entre dos adolescentes enardecidos por la Naturaleza ${ }^{23}$.

Una reflexión final sobre el tema del gitanillo: A través de esta historia nos encontramos como diversos amigos-as franceses malinterpretan la supuesta confidencia de Picasso y un amigo compatriota aparentemente la censura. Parábola fiel de la fortuna crítica que tuvo Picasso durante su vida: nunca bien comprendido en su país de adopción y cerrilmente censurado en el propio.

\section{El cuadro del hombre desnudo de espaldas. Font el guardabosques de Horta}

De la autenticidad de este segundo cuadro como obra de Picasso no puede caber la menor duda, pues, las analogías con obras coetáneas picassianas son muy claras y varias. (Ver especialmente el dibujo procedente del Círculo Artístico de Barcelona (1899), de la Mujer desnuda, con un pie sobre una silla, del Museo Picasso de Barcelona, MPB 110.595). Me remito al artículo que lo dio a conocer en la revista Goya ya mencionado. Palau destaca entre otras facetas «el desparpajo con el que es acometida pictóricamente la figura me parece típicamente picassiano y algunos detalles como la pincelada romboidal que aparece en la nalga izquierda son detalles que ya anuncian los rasgos del creador del cubismo" (Picasso Académico..., págs. 120 y 141). Y más adelante "tanto la ventana o ventanal de la izquierda, como el mueble de la derecha son inequívocamente picassianos (especiamente Ventana del MPB 110.218)». Pero nos interesa ahora resaltar la riqueza de ideas pictóricas originales que aporta esta obra siendo, a su vez, eslabón en la cadena antropomórfica que progresa hacia soluciones que situaran a su autor tres años después, en primera línea de la vanguardia. Picasso ha colocado al viril modelo en una postura clásica de academia, pero como ha tenido que improvisar una clase en Horta, se las ha ingeniado para que sus piernas se afirmen sobre «la repisa de un mueble» como intuye certeramente Palau. Por eso no vemos la típica plataforma circular de las clases oficiales.

A Picasso le interesa, ahora, experimentar con los efectos de la luz definitoria del perfil y de seguir estudiando los relieves de la columna y los homoplatos y sus posibilidades pictóricas que, probablemente, intuyó por vez primera en La Coruña, cuando realizó aquel virtuoso dibujo al carbón de un vaciado del Torso desnudo, de espaldas (Z.VI.1). Ya en la Escuela Oficial de Bellas Artes de Barcelona había dejado constancia de su interés por el tema, con una escueta representación de una Espalda (MPB 110.069) que Palau, que la reproduce en Picasso Academic (pág. 33. ¡Ver también fig. 30!), califica de espléndida. Y en Madrid, en las clases del Círculo de Bellas Artes en un asombroso dibujo de Mujer desnuda (MPB 111.329) (Fig. 14), que por cierto es la

\footnotetext{
23 Palau cree que «lo del gitanillo, en todo caso, es evidente que no puede pasar de ser que una escaramuza de adolescentes sin consecuencias sexuales concretas». (Carta a E.G.H. de 26-6-95). En "Picasso Academic...", pág. 67, Palau sin mencionar ni culpar a la Gilot dice que «algunos han explotado esta figura [del gitanillo] y la han convertido en leyenda insinuando incluso la pederastia, pero que para él se trataría solo de bromas procaces entre muchachos jóvenes». Y en todo caso, aquel posible amor homosexual del verano del 98, ¿es qué disminuye o afea la imagen de la personalidad histórica de Picasso? Mas bien acentúa su compeljidad.
} 
primera modelo femenina desnuda de su vida, de que existe constancia, traza casi geométricamente el cuerpo femenino con la columna hendida y al mismo tiempo un pie de forma, enequívocamente, triangular que es otra idea que también reaparece potente en la pintura que estamos analizando.

Resumiendo el proceso, al otro extremo de la evolución están los cuadros «azules» de Barcelona, 1902, Dos mujeres en la taberna y el Desnudo azulacurrucado, donde las hendiduras de las espaldas se convierten en la idea dominante. John Richardson que no cree demasiado en la originalidad del talento de Picasso joven, atribuye la paternidad de esta idea a Gauguin que «abrió los ojos de Picasso a las posibilidades expresivas de una espalda" (cuyo cuadro Vahine ne te miti, de 1892 reproduce como ejemplo. Ibid., pág. 240). El destino final de la evolución del pie triangular era, desde luego, el cubismo pasando por Les Demoiselles d'Avignon con el pie monstruoso de la mujer de la izquierda. La cuarta idea que se afirma en esta pintura de Horta, es la de la ventana que emerge como motivo único en un dibujo de Madrid (MPB 111-353) y aquí aparece lateralizada para devenir unos meses más tarde en Barcelona, figura central otra vez en las dos pequeñas pinturas del Museo Picasso de Barcelona, en las que se observan las mismas «matizaciones de color en sus tres zonas», según observa Palau. Del mismo año y lugar proceden dos cuadros esenciales, a los que ya hemos aludido antes, donde las ventanas laterales ya están compuestas con más entidad pictórica y con menos funcionalidad lumínica, pues, Picasso ya se va despojando del lastre académico: Lola junto a la ventana (Fig. 15) y el Retrato de Juan Cardona. La ventana esquemática reaparece en la resolución de un cuadro paradigmático parisino de 1901, La Habitación azul, cuadro en el que la luz lateral procedente de una ventana muy semejante a las anteriores, baña espectral, idealmente, un interior donde una mujer se baña en una palangana junto a una cama. Era el estudio alojamiento de Picasso en París cuando vivía con Pere Manyac. Es la misma invención pictórica aplicada a una visión no naturalista. Después, la ventana lateral, ya como recurso compositivo o como complemento narrativo, aparece en numerosas obras como 1925 Tres Bailarines, 1932 Marie Therese junto a la ventana, incluso 1937 Guernica.

Palau revela el arranque de otra idea típica picassiana que él ve ya claramente formulada aquí: el usar técnicas distintas - una accidentada y otra "lisa»- para pintar partes diferentes (en este caso, la superior e inferior del hombre), del mismo cuadro. De esta dualidad técnica es ejemplo el Retrato de Corina Romeu (1902), cuya cabeza es de pintura «apretada», mientras que los hombros y pecho los resuelve en toques sueltos y se vale de ella para acentuar las diferencias y las tensiones entre sendos lados, derecho e izquierdo de Les Demoiselles d'Avignon (1907). En realidad, esta técnica es una derivación de su gusto (¿su capricho?) por dejar alguna parte del lienzo sin pintar, que ya es notorio en la Muchacha descalza de La Coruña de 1895. En El Pintor y su modelo (Olga), del verano de 1914 y en el precioso Retrato de su hijo Paolo vestido de Arlequín de 1924, la idea llega a su expresión más atrevida, pues combina partes perfectamente terminadas con otras sólo abocetadas y sin color. Más adelante, hará amplio y variado uso de esta personal manera en sus grabados de la suite Vollard y, se puede percibir, incluso en la escultura de El Hombre del Cordero de 1943, muy insistida la parte superior, esquemática la inferior...

Pero ello no indica que Picasso tenga ya un método que aplica conscientemente, sino más bien que va ganando confianza en hacer lo que - como dirá mucho más tarde-, le va pidiendo la obra que tiene entre manos. Si, como en el retrato de Paolo, el resultado final puede caer en el remilgamiento, prefiere dejar sin terminar la silla. A veces como en el caso de la escultura lo hizo por pura necesidad.

Hay que aludir a otro descubrimiento, aunque se trate de una hipótesis, que debemos al agudo investigador catalán. Se trata de la identificación del modelo del cuadro Hombre desnudo de espaldas. Palau explica en su estudio transcrito y traducido en "Picasso Académic», que se «inclina a creer que el modelo es un personaje de Horta llamado Font que era guardabosque». La 


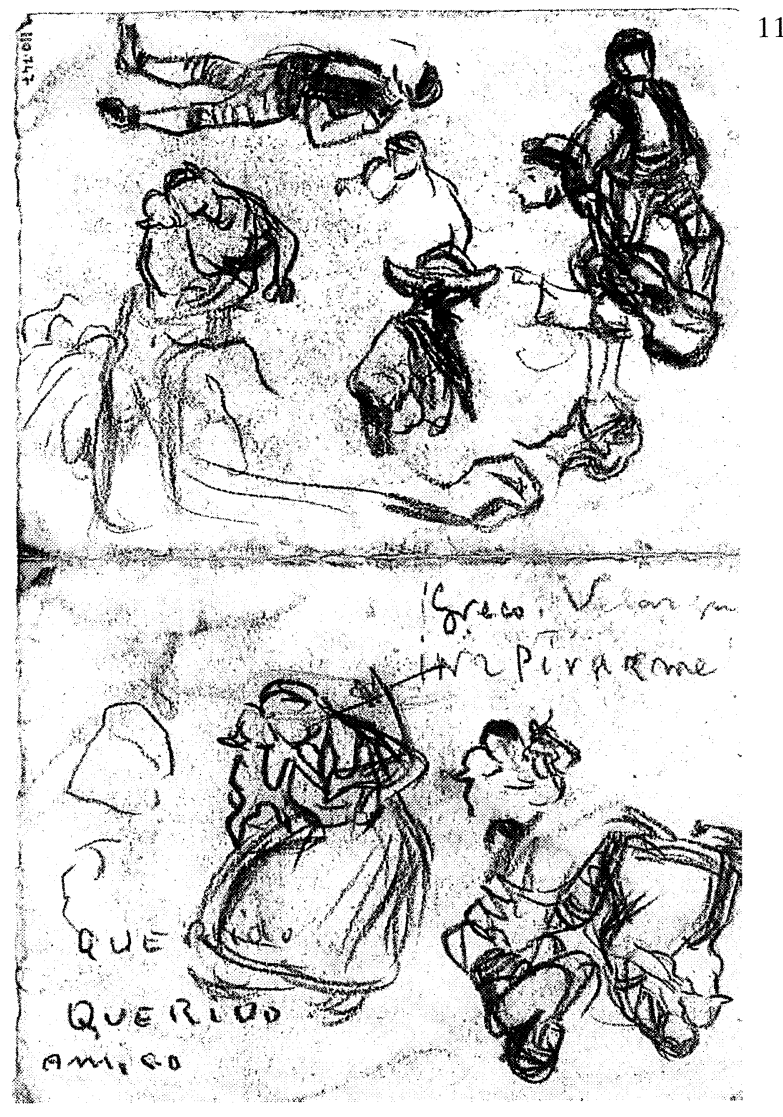

11

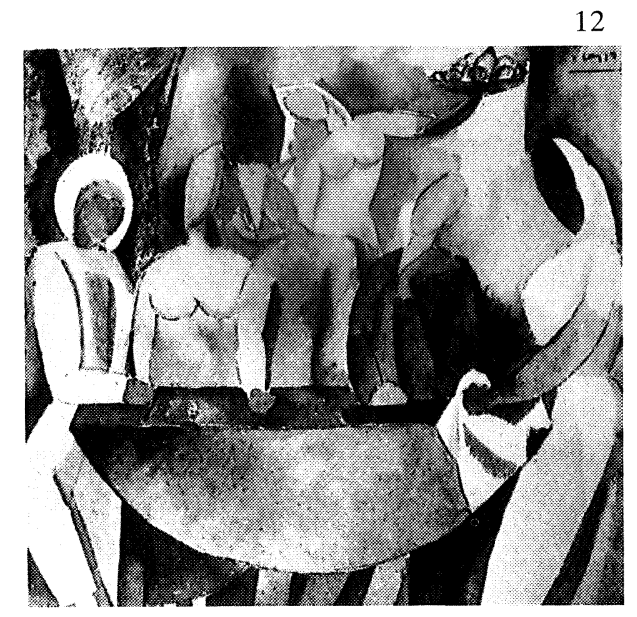

13
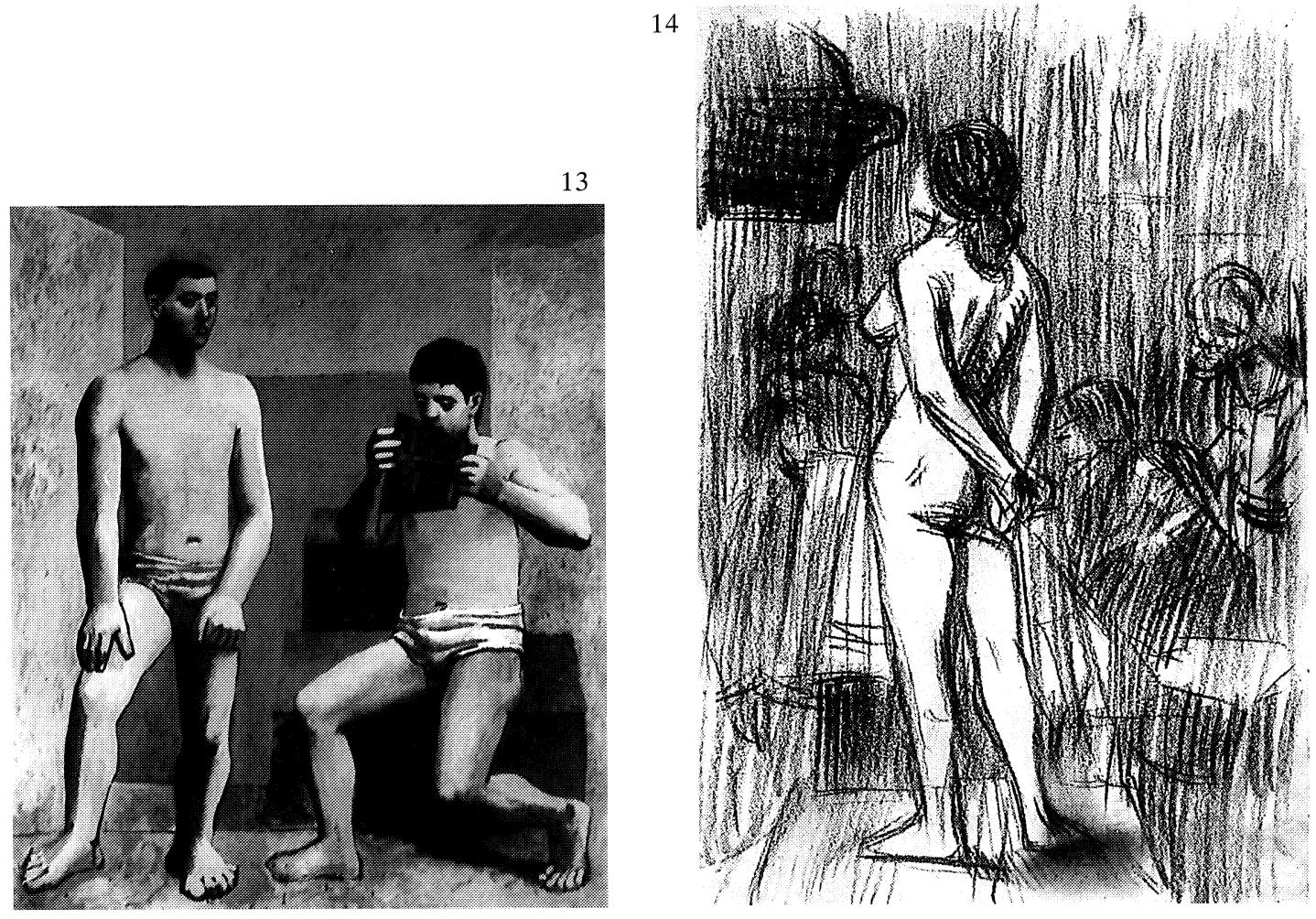

Fig. 11. Diversos tipos aragoneses, Barcelona, Museo Picasso.

Fig. 12. Carnaval en la taberna. Herederos del artista.

Fig. 13. La flauta de Pan. París, Museo Picasso.

Fig. 14. Mujer desnuda. Barcelona, Museo Picasso. 
prueba principal es «la foto que durante su segunda estancia en Horta, en 1909, le hace Picasso a Font, el guardabosque (Picasso Photograph, Anne Baldassari, n. 119, Musée Picasso, Paris) (Fig. 16).

"Aunque aquí le vemos vestido, la estrucura de su rostro y de su cuerpo (el cogote y los hombros algo caídos) es la misma. Picasso no le ha fotografiado de espaldas porque sí, sino adrede, con la intención de evocar la pose antigua y para que podamos reconocerle» (Ibid., 141).

En abril de 1996, hice una visita a Horta (Fig. 4), segunda en cinco años. Había pedido al señor Joaquim Ferrás, director del Centre Picasso de Horta, que me pusiera en contacto con algún superviviente de la época de Picasso y tuve la fortuna de conocer y hablar extensamente con don Juan Vives Gil, hijo de Joaquín Antonio Vives Terrats, que Picasso utilizó como modelo en varias obras cubistas de 1909, y muy especialmente en el cuadro conocido como El Atleta. Ferrás había citado a Vives en el Centre Picasso, que éste dijo no haber visitado nunca antes (Fig. 17). Pocos momentos después de las presentaciones, este anciano muy alerta y de buena salud, reconoció inmediatamente a Font, el guardabosques, en la fotografía del hombre con un galgo al lado, del libro «Picasso photographe» al que se refiere Palau. «Es el señor Font, el guardamontes. Como si lo estuviera viendo.» Después se plantó delante de la reproducción del cuadro del Hombre desnudo de espaldas, que está instalada en este museo de reproducciones de obras realizadas por Picasso en Horta, y después de mirarlo fijamente lo identificó, igualmente, con la misma persona que él había conocido de niño. «Ese es Font», dijo sin vacilar. Luego nos explicó: «Font era un hombre grande, muy fuerte. Tenía los hombros así, caídos y unos grandes bigotes. Llevaba polainas y una gorra como en la fotografía. Venía mucho al Café de mi padre que le llamaban el "Café de la Música", porque tanto mi padre, como mi abuelo tocaban la música y fueron directores de la Banda del pueblo. Me acuerdo que Font me daba, a veces, una perra gorda para que me comprase caramelos.» «El señor Font me parece que era de Gerona. Tenía un acento catalán más cerrado, como de por allá. Se fue de Horta poco antes de la República» (14 de abril 1931). El señor Vives dice tener 76 años, con lo que su edad hacia 1930 o 31 serían de diez o once años. Luego le pregunté por el gitanillo y le mostramos la reproducción correspondiente. Me dijo, que siempre había habido gitanos en Horta y que recordaba de antes de la guerra civil, al gitano Pindangues y su mujer Custodia que eran muy populares en el pueblo. Que ahora todavía hay alguna familia de gitanos; que eran gente que no se mezclaban apenas con el resto de la población, pero que estaban bien considerados y respetados por todo el mundo, dedicándose a trabajos diversos, como la recolección de frutas lo cual confirmó Ferrás. Vives, después de observar el cuadro del gitanillo, insinuó que se parecía algo a un muchacho gitano, que vive en el término de Horta. De la estancia de Picasso en 1909 referió cosas que sabía por su padre y que en general ya están divulgadas. Le hice varias fotos en el Centre Picasso, una de ellas posando junto a la estampa del cuadro de su padre lo que le agradó mucho. También me dijo que él tenía buena memoria para nombres, porque había trabajado muchos años como oficial administrativo, en el Ayuntamiento de Horta, anotando todos los nacimientos y defunciones. Como se trata de una persona distinta a la que Palau mostró el libro con las fotografías de Picasso, se refuerza el valor de la identificación del guardabosques de Horta en el retrato fotográfico de Picasso ${ }^{24}$.

\footnotetext{
24 Este importante testimonio resuelve definitivamente la cuestión sobre la identidad del modelo de Picasso para el cuadro El Atleta y la fotografía del guitarrista. Creemos por otra parte que Fernando Olivier en sus cartas desde Horta $a$ Alice B. Tocklas y G. Stein, citadas por J. Richardson Ibid. vol II, p. 131 y notas, al mencionar al guardia civil puede estar refiriéndose al guardabosques que tambien iba uniformado.
} 

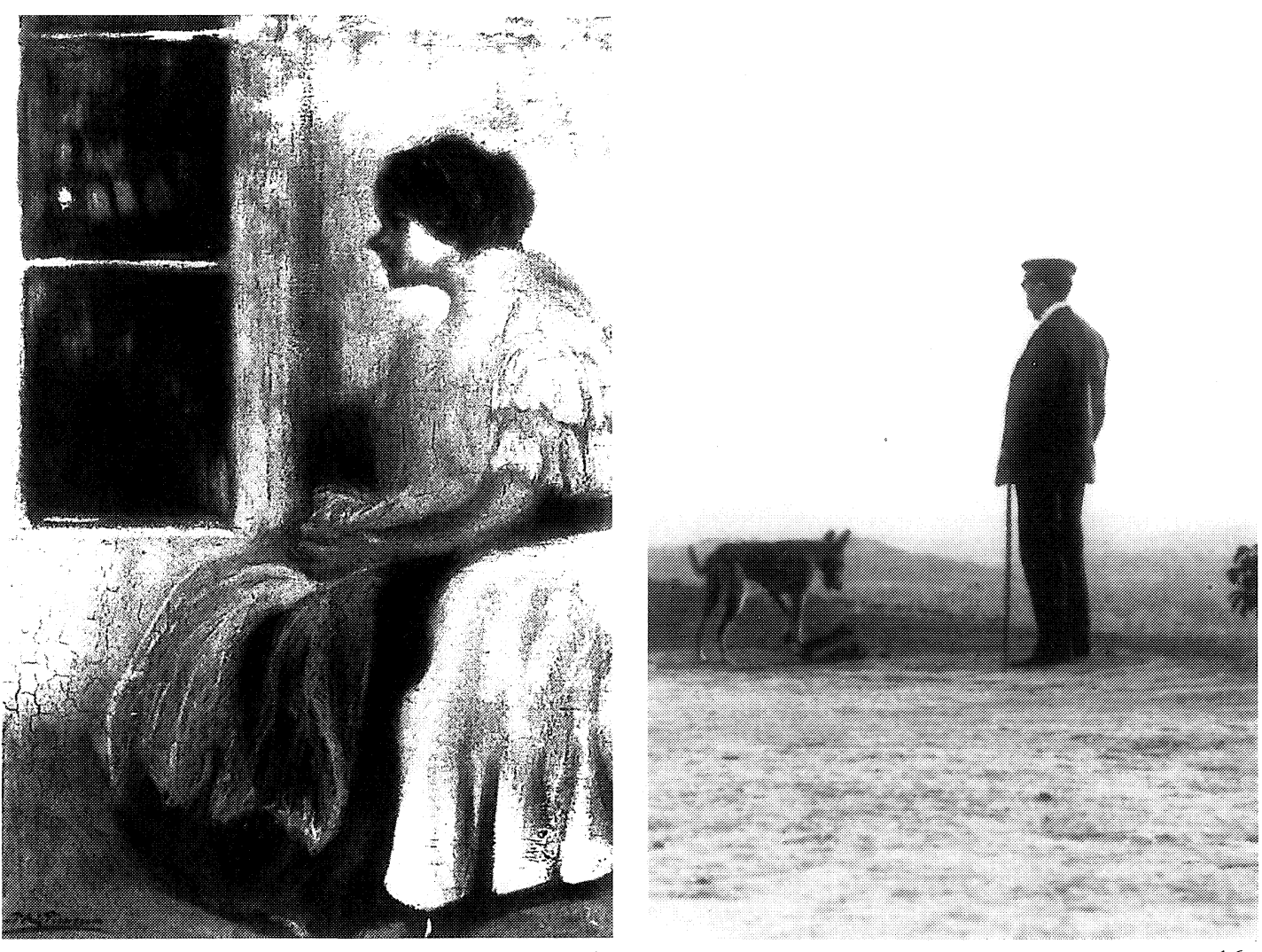

15

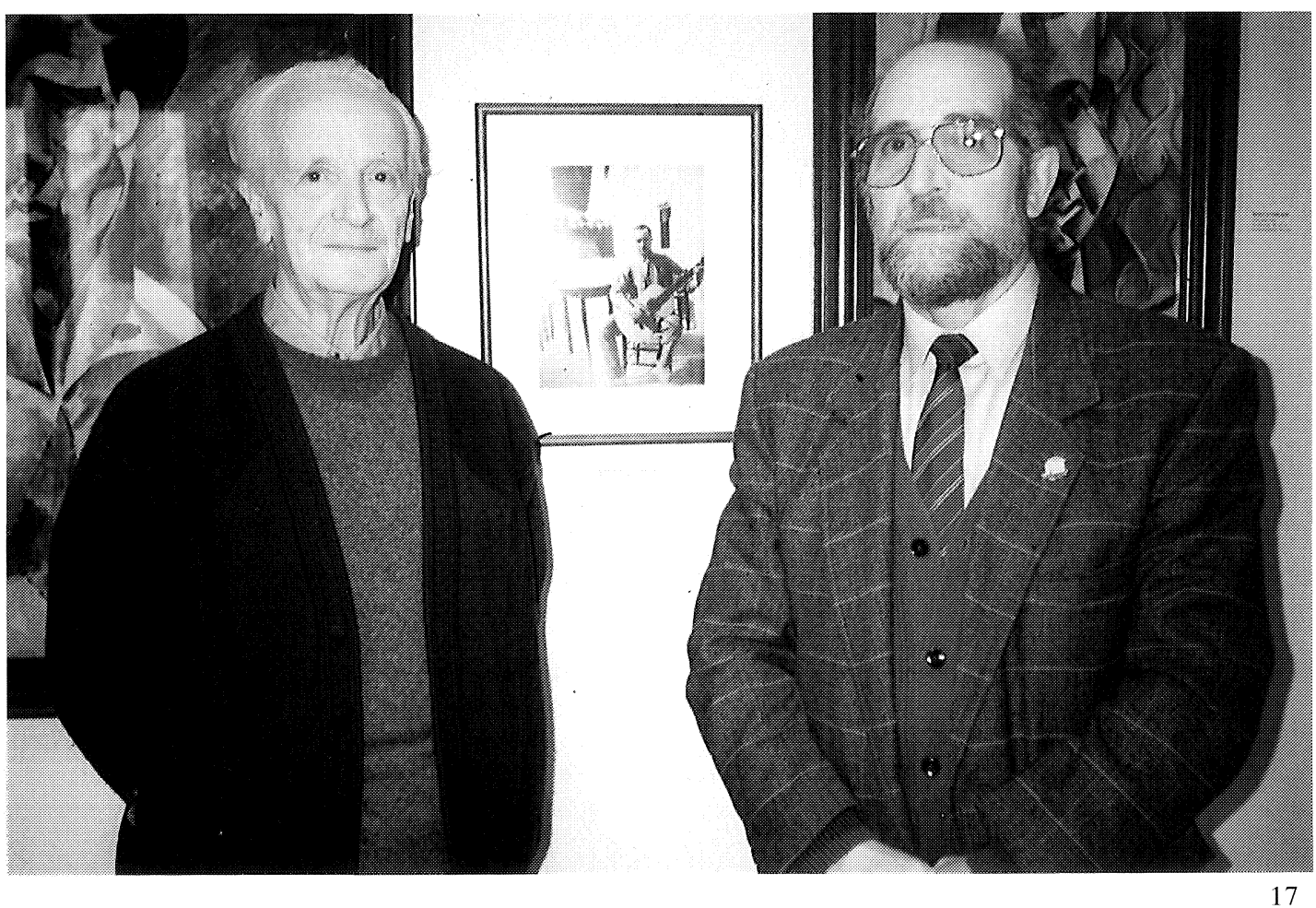

Fig. 15. Lola junto a la ventana. Herederos del artista.

Fig. 16. Horta, 1909, fotografía de Picasso.

Fig. 17. Juan Vives y Joaquim Ferrás en el Centre Picasso de Horta, 1909 (fotografía del autor). 